\title{
Wie können Kinder in der Schule besser zuhören?
}

\section{Elterninformation}

Die meisten Kinder mit auditiven Verarbeitungs- und Wahrnehmungsstörungen können besser zuhören, wenn einerseits der Klassenraum eine "akustikfreundliche Hörumgebung" hat und andererseits die Lehrerin/der Lehrer auf einen wahrnehmungsfördernden Unterrichtsstil achtet. Nachstehend finden Sie einige Vorschläge, wie Schulkindern das Zuhören erleichtert werden kann.

\section{Störgeräusche und Nachhall}

Heizungs- oder Kühlungssysteme produzieren häufig Störungsgeräusche, ebenso wie Leuchtstoffröhren, Lampen, Uhren, Fischaquarien und Computer. Wenn möglich, sollten solche mechanischen oder maschinengenerierten Geräusche auf ein Minimum reduziert werden. Flure mit harten Oberflächen sollten mit Teppichböden belegt sein, möglichst mit trittschalldämmenden Unterteppichen oder Folien. Alternativ sollten zumindest größere Teppiche gelegt werden. Akustische Decken können gut Störgeräusche absorbieren. Die Raumhöhe sollte niedriger als $3,50 \mathrm{~m}$ sein. An der Decke aufgehängte Tücher o.ä. können helfen, den Störschall bzw. den Nachhall zu dämpfen.

Da Glas einen harten akustischen Widerstand bietet, reflektieren große Glasflächen Schall. Dies kann zumindest teilweise mit Gardinen, Jalousien oder Rollos verringert werden. Während mündlicher Instruktionen sollten die Fenster geschlossen sein. Von den Schülern selbst hergestellte Teppiche, Korkplatten oder ähnliches schallabsorbierendes Material können die Schallreflektion an Wänden verringern. Bei Renovierungen sollten schalldämmende Türen bevorzugt werden. Quietschende Schlösser sind zu ölen. Besonderes Augenmerk muss darauf gerichtet werden, ob Umgebungslärm vom Flur in ungebührlichem Maße in den Klassenraum dringen kann. Falls die Klassen- räume nicht mit Teppichboden ausgelegt sind, sollten die Schreibtischfüße entsprechend modifiziert werden, z.B. sollten Fußbodenschoner angebracht werden, um Schleifgeräusche $\mathrm{zu}$ vermeiden. Schubladen können mit schalldämpfendem Material ausgelegt werden, damit nicht so viel Lärm entsteht, wenn Kinder in Schubladen nach Utensilien suchen.

\section{Sitzplatzauswahl \\ $\checkmark$}

Einige Kinder haben eine ausgeprägte "Ohrigkeit", d.h. sie hören und verstehen auf einem Ohr deutlich besser als auf dem anderen. Diese Kinder sollten so sitzen, dass das "bessere" Ohr dem Lehrer zugewandt ist. Die Sitze sollten so platziert werden, dass Kinder das Gesicht des Lehrers deutlich sehen können, mit einem Winkel nicht größer als $45^{\circ}$.

\section{Hinweise für Pädagogen $\nabla$}

Damit die Kinder besser dem Unterricht folgen können, sollte die Lehrerin/der Lehrer

- sich der Aufmerksamkeit des Kindes vergewissern, wenn wichtige Instruktionen gegeben werden. Verbale und taktile Hinweise können nützlich sein.

- beachten, dass die Zeitintervalle, die intensives Zuhören erfordern, der Aufmerksamkeitsleistung des Kindes angemessen sind.

- das Kind beim Reden anschauen.

- eine überhöhte Sprechgeschwindigkeit vermeiden.

- natürliche Pausen im Sprechfluss einhalten, insbesondere die Möglichkeit zum Fragenstellen zu geben.

- ausdrucksvoll, aber nicht mit übertriebener Prosodie sprechen.

- sich darüber bewusst sein, dass Gesten, insbesondere ausdrucksvolle Mimik, dazu beitragen, zusätzliche Hinweise zum Verstehen des Gesagten zu geben.
- wichtige Mitteilungen von Informationen mehrfach wiederholen.

- wichtige Konzepte oder wichtige neue Worte vorher erklären.

- vor der eigentlichen Aufgabe, die intensives Hören und Zuhören verlangt, den Schülern Stichpunkte mitteilen, um ein strukturiertes Hören zu ermöglichen.

- beim Schreiben an der Tafel nicht sprechen und keine Anweisungen geben (indirekter Schall, kein Sichtkontakt).

- Kettenanweisungen vermeiden.

- idiomatische Ausdrücke vermeiden.

- Zeiträume einplanen/"freigeben", um z.B. Buntstifte zu spitzen, Papiere einzusammeln, Bücher auszuteilen, etc., und während dieser Zeit keine kritischen neuen Informationen geben.

- Schlüsselwörter und Konzepte an die Tafel schreiben.

- die Bedeutung neuer Worte ausführlich schildern und diese dann häufig verwenden.

- den Kindern mit einer auditiven Verarbeitungs- und Wahrnehmungsstörung erlauben, dass ein Mitschüler Stichwörter aufschreibt, während das Kind nur versucht, adäquat zuzuhören.

\section{Fazit}

Um Kindern mit auditiven Verarbeitungs- und Wahrnehmungsstörungen beim Zuhören zu helfen, sollte auf eine geräuscharme Umgebung und einen wahrnehmungsfördernden Unterrichtsstil geachtet werden.

Prof. Dr. Dr. Martin Ptok, Hannover, Prof. Dr. Annette Leonhardt, München überreicht durch Thieme und 